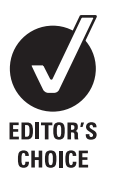

${ }^{1}$ California Office of

Environmental Health Hazard Assessment, Oakland, California, USA; ${ }^{2}$ University of California, Davis, California, USA;

${ }^{3}$ University of California, San Francisco, California, USA

Correspondence to:

Dr Bart Ostro, Chief, Air Pollution Epidemiology Section, OEHHA, 1515 Clay St, 16th Floor, Oakland, California 94612, USA; bostro@oehha.ca.gov

Accepted 8 February 2008 Published Online First 16 April 2008

\title{
The impact of components of fine particulate matter on cardiovascular mortality in susceptible subpopulations
}

\author{
B D Ostro, ${ }^{1}$ W-Y Feng, ${ }^{2}$ R Broadwin, ${ }^{1}$ B J Malig, ${ }^{1}$ R S Green, ${ }^{1}$ M J Lipsett ${ }^{3}$
}

\begin{abstract}
Background: Several studies have demonstrated associations between daily mortality and ambient particulate matter less than 2.5 microns in diameter (fine particles or PM2.5). Few, however, have examined the relative toxicities of PM2.5 constituents, including elemental carbon and organic carbon (EC and OC, respectively), nitrates and transition metals. There is also little information about whether associations between PM2.5 constituents and mortality are modified by socioeconomic and demographic factors.
\end{abstract}

Aim: To examine associations of daily cardiovascular mortality with PM2.5 and its constituents after stratification by gender, race/ethnicity and education, using data from six California counties during 2000 to 2003.

Methods: The association of daily counts of cardiovascular mortality with PM2.5 components was analysed using time-series regression analyses. Poisson models with natural splines were used to control for time-varying covariates such as season and weather. Separate models were run after stratification by gender, race/ethnicity (White, Hispanic, Black) and education (high school graduation or not). Models were run for each county and results were combined using random effects metaanalysis.

Results: Daily counts of cardiovascular mortality were associated with PM2.5 and several of its species including EC, OC, nitrates, sulphates, potassium, copper and iron. For many of these species, there were significantly higher effect estimates among those with lower educational attainment and Hispanic individuals. For example, while essentially no association was observed for individuals who graduated from high school, an interquartile change in several of the components of PM2.5 was associated with a $3-5 \%$ increase in daily mortality among non-high school graduates.

Conclusion: There is evidence that several PM2.5 constituents may represent important contributors to cardiovascular mortality. Many of these constituents are generated by motor vehicles, especially those with diesel engines, and by residential wood combustion. In addition, factors associated with low educational attainment may increase susceptibility to PM2.5 and its components.

Several multi-city time-series analyses have demonstrated associations between daily mortality and ambient fine particulate matter (particles less than 2.5 microns in aerodynamic diameter or PM2.5). ${ }^{12}$ There is limited information, however, about associations of daily mortality with components of PM2.5, such as transition metals and elemental carbon and organic carbon (EC and OC, respectively). ${ }^{34}$ In addition, little is known about such associations among demographically distinct and potentially susceptible subpopulations (eg, different racial groups).

Information on both the toxicity of PM2.5 components and susceptibility of subpopulations may be important for several reasons. First, identification of specific PM2.5 constituents that may be more strongly associated than total PM2.5 mass with mortality would facilitate the targeting of pollution control efforts. Second, in multi-city studies of particulate matter and daily mortality, analyses have demonstrated inter-city heterogeneity. ${ }^{5}$ Characterising differential population susceptibilities and PM2.5 component toxicities could help explain some of this heterogeneity in terms of differences in physico-chemical composition of particle mixtures and/or demographic characteristics. Third, the substandard health status of economically disadvantaged communities has been well documented, ${ }^{67}$ as has the occurrence of disproportionate air pollution exposures in neighbourhoods with high levels of poverty. ${ }^{8}$ Therefore, residents of these neighbourhoods may be differentially affected both because of locally elevated air pollution exposures and because of poverty-related factors that may enhance susceptibility to pollution, such as poor nutrition and reduced access to quality healthcare.

In this paper, we examined whether gender, race/ethnicity and educational attainment modified relationships between daily mortality and species of PM2.5 in six California counties.

\section{METHODS}

\section{Mortality data}

We obtained data on daily mortality for all California residents from the California Department of Health Services, Center for Health Statistics (CDHS) from 1 January 2000 to 31 December 2003. Data were limited to deaths occurring in the decedents' counties of residence. Daily counts of deaths from cardiovascular disease (International Classification of Diseases, Tenth Revision (ICD10) = I00-I99) were calculated and also aggregated for several sociodemographic groups, including males, females, white, Hispanic, and black residents, individuals having less than a high school education and those having at least a high school education. Race and ethnicity were two separate questions in the CDHS mortality database. Our definition of Hispanic was similar to that used by the CDHS, where the coroner or next of kin indicate a positive response to the question of Hispanic ethnicity. A person of any race or races 
may be of Hispanic origin; approximately $80 \%$ of Hispanic individuals were Mexican/Chicano, 10\% were Central- or South American, 3\% were Cuban and 2\% were Puerto Rican. We defined both White and Black by the first race listed, and by an answer to the Hispanic question marked "not Spanish/ Hispanic". Since few associations were observed for black residents, likely due to low count of daily deaths, this subgroup was dropped from subsequent analysis.

\section{Pollutant and meteorological data}

We obtained PM2.5 speciation data for the 4-year period 2000 to 2003 from the California Air Resources Board (CARB). The speciation monitors were part of the Special Trend Network and the State and Local Air Monitoring Stations network, and were filter-based Speciation Air Sampling Systems (Met One Instruments Inc., Grants Pass, Oregon). We included only the six counties with 180 days or more observations of PM2.5 species data to enhance statistical power throughout the study period. Each of the six counties had two monitors measuring components of PM2.5. In three counties (Fresno, Kern and Riverside), the two monitors were located within $4 \mathrm{~m}$ of each other, while in the other counties (Sacramento, San Diego and Santa Clara) the monitors were not co-located. Fresno, Kern, Riverside and Sacramento counties reported data every third day; San Diego and Santa Clara counties reported data every sixth day. To obtain a daily county pollutant concentration for each species while accounting for missing data, we combined data from the two monitors using the same process as that reported in Ostro et al. ${ }^{3}$ We included only species for which at least $50 \%$ of the observations were above the level of detection.

The following constituents of PM2.5 were measured as 24-hour averages: EC, $\mathrm{OC}$, nitrates $\left(\mathrm{NO}_{3}\right)$, sulphates $\left(\mathrm{SO}_{4}\right)$, calcium $(\mathrm{Ca})$, chlorine $(\mathrm{Cl})$, copper $(\mathrm{Cu})$, iron $(\mathrm{Fe})$, potassium $(\mathrm{K})$, sulphur $(\mathrm{S})$, silicon $(\mathrm{Si})$, titanium $(\mathrm{Ti})$ and zinc $(\mathrm{Zn})$. These PM2.5 components represent multiple sources of PM2.5, primarily gasoline combustion, diesel exhaust, wood smoke, crustal material and secondary pollutants.

To adjust for effects of weather, we obtained daily average temperature and humidity data at meteorological stations in each of the counties from the National Climatic Data Center. ${ }^{10}$

\section{Statistical analysis}

Time-series analysis using Poisson regression was used to model mortality for each stratum (eg, women) conditional on the explanatory variables. A similar model specification was used for each stratum and each city, and included the following timevarying covariates: day of the week, natural cubic smoothing splines of time with four degrees of freedom ( $\mathrm{df}$ ) per year of data, and natural splines of 1-day lags of average temperature and humidity (each with $3 \mathrm{df}$ ). The df were chosen a priori based on their effectiveness in controlling for seasonal and secular patterns in previous studies. ${ }^{11}$ County-specific estimates were initially obtained for each component using singleday lags of 0 to 3 days. The county-specific results were then combined in a meta-analysis using a random-effects mode ${ }^{12}$ for each of the socio-demographic mortality categories (cardiovascular mortality by gender, race/ethnicity and educational attainment). We tested for statistical differences between strata using a t-statistic. ${ }^{13}$ We reported basic results for all lags but focused on the results using lags of 0 and 3 days. Unlike many time-series studies with continuous daily data, not all lags refer to the same outcome of days. Specifically, for species data collected every third day, lags of 0 and 3 days will refer to the same days (and numbers of deaths/day). In contrast, for those same PM data, lags 1 and 2 refer to different mortality days. While this phenomenon holds true for other studies using nondaily PM data, the number of observations used in this analysis are small relative to those in most published studies of PM and mortality, so the results may be more sensitive to the mortality days used.

All final results were calculated using $\mathrm{R}$ software (version 2.5.0: R Development Core Team). To compare relative impacts based on observed concentrations, the results are presented as the excess risk (ie (relative risk -1$) \times 100$ ) in daily mortality for the interquartile range (IOR) of the pollutants.

\section{RESULTS}

Tables 1 and 2 provide descriptive statistics for mortality categories, air quality, and meteorological data from six counties with component data. Mean daily cardiovascular mortality ranged from 5.1 deaths in Kern county to 20.3 deaths in San Diego county (table 1). Mean daily PM2.5 concentrations over the study period ranged from $12.6 \mu \mathrm{g} / \mathrm{m}^{3}$ in Sacramento county to $27.1 \mu \mathrm{g} / \mathrm{m}^{3}$ in Riverside county (table 1). Four of the six counties exceeded the US EPA annual average PM2.5 standard of $15 \mu \mathrm{g} / \mathrm{m}^{3}$, and all six exceeded the California annual average standard of $12 \mu \mathrm{g} / \mathrm{m}^{3}$. As shown in table 2, the four largest components of PM2.5 were EC, OC, $\mathrm{NO}_{3}$ and $\mathrm{SO}_{4}$, which constituted approximately $5 \%, 37 \%, 28 \%$ and $10 \%$ of total PM2.5 mass, respectively. Moderate-to-high correlations $(\mathrm{r}=0.4-0.6)$ were found between PM2.5 and $\mathrm{EC}, \mathrm{OC}, \mathrm{NO}_{3}, \mathrm{~K}$ and $\mathrm{Zn}$. More modest correlations $(\mathrm{r}=0.2-0.4)$ were observed between PM2.5 and $\mathrm{SO}_{4}, \mathrm{Ca}, \mathrm{Cu}, \mathrm{Fe}, \mathrm{S}$ and Ti. Between species, correlations generally ranged from 0.20 and 0.45 , with a few exceptions such as EC with OC (0.61), Fe (0.48), K (0.48) or Zn (0.53), OC with $\mathrm{Zn}(0.50)$, and $\mathrm{SO}_{4}$ with $\mathrm{S}(0.85)$ (see Ostro et al, 2007 for a full set of correlations). ${ }^{3}$ Over the 4 years, there were a total of approximately 1870 observation-days across the six counties for most of the species.

Table 3 summarises the results of the meta-analysis examining cardiovascular mortality in relation to pollutant lags of 0 to 3 days. Positive associations were observed involving various subgroups and lags of several species. Frequent associations were observed for PM2.5, EC, OC, $\mathrm{NO}_{3}, \mathrm{SO}_{4}, \mathrm{Fe}, \mathrm{K}, \mathrm{S}$, Ti and $\mathrm{Zn}$. Among the subgroups, many more associations were observed for non-high school graduates. Associations were also more evident for females, and for both white and Hispanic people. Figures 1 and 2 summarise the quantitative metaanalytic risk estimates for cardiovascular mortality for the race/ ethnicity and education subgroups. The figures demonstrate that the quantitative differences in excess risks between some of the subgroups are substantial. For example, excess risks for Hispanic people ranged from 2.5 to $6 \%$ for many of the species versus 0 to $2 \%$ for white people. By education, the differences were even greater. There were essentially no significant associations observed for high school graduates, with statistically significant excess risks of $2-6 \%$ among those who have not graduated from high school. The examination by gender indicated few differences in risk for males versus females.

Table 3 also provides a summary of the lags for which there were statistically significant effect estimates between subgroups. For example, for cardiovascular mortality, statistically different risk estimates were observed for non-high school graduates versus graduates for $\mathrm{PM} 2.5, \mathrm{EC}, \mathrm{OC}, \mathrm{NO}_{3}, \mathrm{SO}_{4}, \mathrm{Cu}$, Fe, K, S, Si and Ti. Similarly, statistically significant differences were observed between Hispanic and white people for PM2.5, 
Table 1 Mean daily deaths, air quality and meteorological data by county, 2000-2003

\begin{tabular}{lcccccc}
\hline Mortality category* & Fresno & Kern & Riverside & Sacramento & San Diego & Santa Clara \\
\hline All-cause, all modifiers & 13.4 & 11.4 & 28.8 & 22.0 & 49.5 & 21.3 \\
Total cardiovascular & 5.8 & 5.1 & 13.2 & 9.3 & 20.3 & 8.7 \\
$\quad$ Male & 2.7 & 2.5 & 6.5 & 4.4 & 9.6 & 4.1 \\
Female & 3.1 & 2.6 & 6.7 & 4.9 & 10.7 & 4.6 \\
White & 4.2 & 4.0 & 11.0 & 7.2 & 16.5 & 6.4 \\
Black & 0.3 & 0.3 & 0.6 & 0.8 & 0.9 & 0.2 \\
Hispanic & 0.9 & 0.7 & 1.2 & 0.5 & 1.9 & 0.9 \\
High school graduate & 3.4 & 2.9 & 9.4 & 6.7 & 15.2 & 6.3 \\
Not high school graduate & 2.2 & 2.1 & 3.4 & 2.4 & 4.4 & 2.3 \\
County characteristics & & & & & & \\
Population $(1000 \mathrm{~s})$ & 799 & 662 & 1545 & 1223 & 2814 & 1683 \\
Mean PM2.5 $\left(\mu \mathrm{g} / \mathrm{m}^{3}\right)$ & 17.5 & 19.5 & 27.1 & 12.6 & 15.3 & 13.9 \\
Mean temp $\left({ }^{\circ} \mathrm{F}\right)$ & 64.2 & 65.7 & 65.5 & 61.8 & 61.9 & 59.5 \\
Mean humidity $(\%)$ & 56.5 & 58.2 & 62.6 & 66.1 & 75.8 & 68.3 \\
Observations & 355 & 281 & 279 & 395 & 243 & 317 \\
\hline PMi particu & & & & & &
\end{tabular}

PM, particulate matter.

*Some columns do not add up due to rounding, omitted subgroups (Asians or "other") or definitions (ie, high school graduation is based on status of those aged $\geqslant 25$ ).

$\mathrm{NO}_{3}, \mathrm{SO}_{4}, \mathrm{Cl}, \mathrm{Cu}, \mathrm{K}$ and $\mathrm{Ti}$. Generally similar results were observed for all-cause mortality (data not shown).

\section{DISCUSSION}

In this time-series analysis of daily mortality in six counties in California, we detected associations between several components of PM2.5 and cardiovascular mortality. We also found effect modification by several demographic characteristics, including race/ethnicity and education. Specifically, we found large, statistically significant differences in excess risk estimates for Hispanic individuals and for non-high school graduates. These differences in excess risks of mortality were associated with PM2.5 mass and with several fine particulate constituents, including $\mathrm{EC}, \mathrm{OC}, \mathrm{NO}_{3}, \mathrm{SO}_{4}, \mathrm{Cu}, \mathrm{K}$ and others. While some results involving certain species and subgroups appear robust, caution in interpretation is warranted due to the relatively small sample size. Multi-city studies have reported associations between mortality and PM2.5, as well as with its components and several broad source categories. ${ }^{1-3} 14$ To our knowledge, this is the first study to examine demographic subgroups that may be more susceptible to PM2.5 components. Our findings are generally consistent with previous research, indicating that primary and secondary products of fuel combustion (EC (an indicator of particles from diesel exhaust), $\mathrm{OC}, \mathrm{SO}_{4}$ and $\mathrm{NO}_{3}$ ) and other measures of mobile source-related emissions ( $\mathrm{Cu}, \mathrm{Fe}$, $\mathrm{Ti}, \mathrm{Zn})$, exhibit the strongest and most consistent associations with mortality.

Several recent studies support the biological plausibility of a link between exposure to EC and OC and exacerbations of cardiovascular diseases. For example, Gold et al found associations of black carbon with ST-segment depression, suggesting myocardial ischaemia, among a panel of 24 elderly Boston residents. ${ }^{15}$ Another recent study examined the relative effects of fine particle components on exercise-induced ischaemia in 45 patients with established heart disease. ${ }^{16}$ Of the five elements examined ( $\mathrm{Si}, \mathrm{S}, \mathrm{Ni}, \mathrm{Cl}$ and $\mathrm{EC}$ ), only EC was associated with ST-segment depression. In a German panel study involving weekly electrocardiograms (ECGs) of 56 men with a history of coronary artery disease, Henneberger and colleagues ${ }^{17}$ identified several associations of ambient EC and OC (within hours of the ECG recording) with changes in myocardial repolarisation, which could increase the probability of sudden death. Thus,

Table 2 Descriptive statistics for PM2.5 mass and species in California counties, 2000-2003

\begin{tabular}{llllll}
\hline Pollutants & Obs* $\left(\mu \mathbf{g} / \mathbf{m}^{3}\right)$ & Mean $\left(\mu \mathbf{g} / \mathbf{m}^{3}\right)$ & $\begin{array}{l}\text { IQR percentile } \\
\text { detection }\end{array}$ & 95th percentile & $\begin{array}{l}\text { Below } \\
\text { detection }(\%)\end{array}$ \\
\hline PM2.5 & 1878 & 19.28 & 14.63 & 46.91 & 0.00 \\
Elemental carbon & 1879 & 0.966 & 0.795 & 2.57 & 0.05 \\
Organic carbon & 1879 & 7.129 & 4.592 & 15.91 & 0.00 \\
Nitrates & 1817 & 5.415 & 5.524 & 17.46 & 0.00 \\
Sulphates & 1817 & 1.908 & 1.530 & 5.18 & 0.00 \\
Calcium & 1870 & 0.080 & 0.064 & 0.20 & 0.05 \\
Chlorine & 1870 & 0.094 & 0.069 & 0.41 & 2.09 \\
Copper & 1870 & 0.007 & 0.007 & 0.02 & 1.34 \\
Iron & 1870 & 0.124 & 0.099 & 0.34 & 0.00 \\
Potassium & 1870 & 0.117 & 0.081 & 0.26 & 0.00 \\
Sulphur & 1870 & 0.648 & 0.499 & 1.70 & 0.00 \\
Silicon & 1870 & 0.168 & 0.151 & 0.43 & 0.05 \\
Titanium & 1870 & 0.009 & 0.008 & 0.02 & 0.32 \\
Zinc & 1870 & 0.012 & 0.011 & 0.04 & 1.82
\end{tabular}

IQR, interquartile range; Obs, observation; $\mathrm{PM}$, particulate matter.

*Total number of observations for analysis across all six counties over the 4-year study period. 
Figure 1 Excess risk of cardiovascular mortality associated with an interquartile range increase in PM2.5 mass and selected PM2.5 components for lag days $\mathrm{O}$ and 3 , stratified by race/ethnicity. $\mathrm{Cu}$, copper; EC, elemental carbon; Fe, iron; IQR, interquartile range; $\mathrm{K}$, potassium; particulate matter; $\mathrm{SO}_{4}$, sulphates; $\mathrm{Zn}$, zinc. ${ }^{*} p<0.10$ and ${ }^{* *} p<0.05$ for difference from null effect. $\mathrm{NO}_{3}$, nitrates; $\mathrm{OC}$, organic carbon; $\mathrm{PM}$

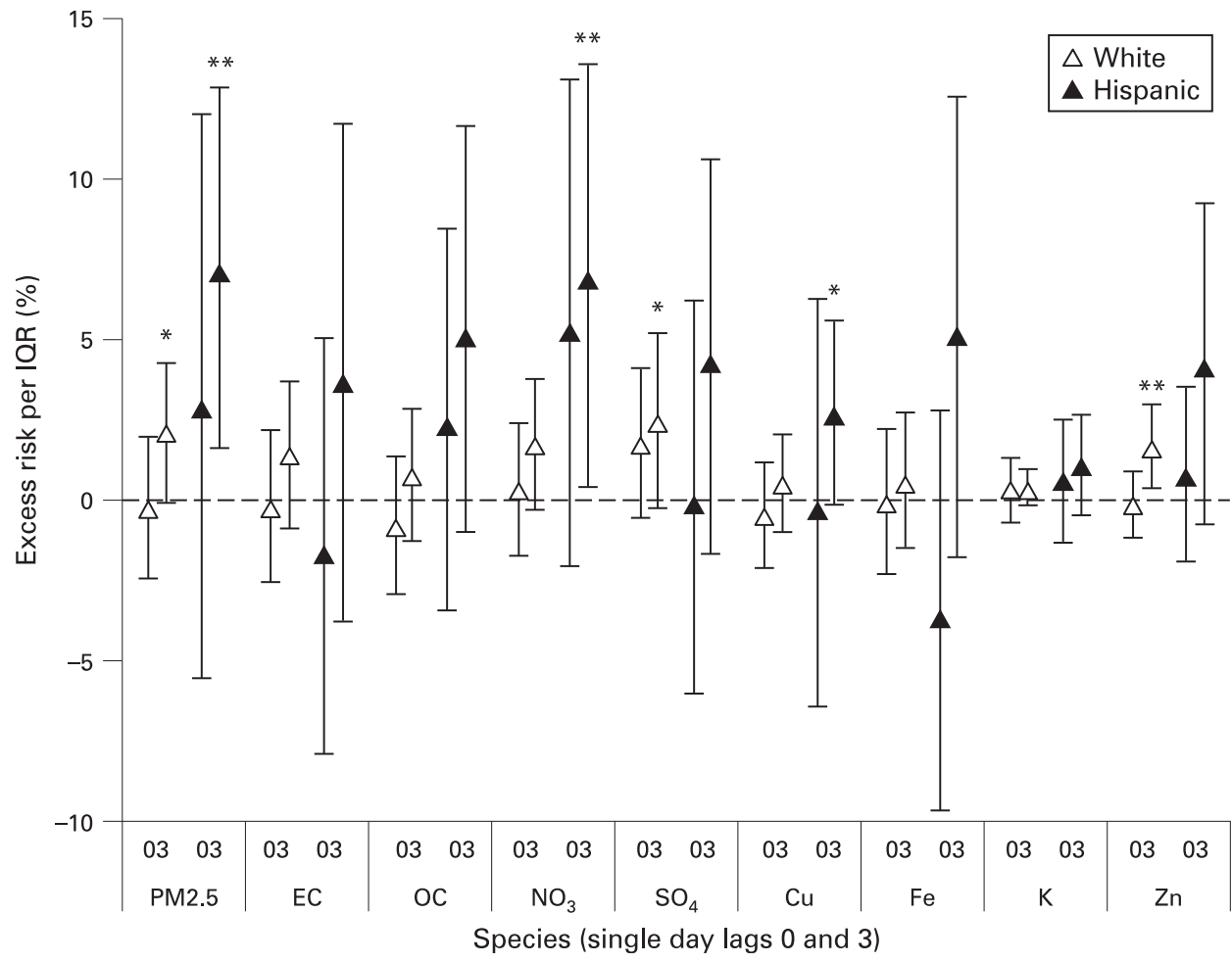

exposures to both EC and OC are associated with a number of indicators that could contribute to cardiovascular disease mortality.

To date, only a few epidemiological studies have examined the relationships of $\mathrm{SO}_{4}$ and $\mathrm{NO}_{3}$ with daily mortality. Most analyses using $\mathrm{SO}_{4}$ have produced positive, and often statistically significant, associations including studies conducted in
Santa Clara County, California, ${ }^{18}$ eight Canadian cities, ${ }^{19}$ and several urban areas on the East coast and in the Midwest. ${ }^{2}$ In addition, in a recent effort to compare results from alternative factor analysis methods to estimate the effects of sources of fine particles, the $\mathrm{SO}_{4}$-related factor was most consistently significant in the cities studied. ${ }^{4}$ In one of the few studies examining $\mathrm{NO}_{3}$, a positive and significant association was detected. ${ }^{18}$
Figure 2 Excess risk of cardiovascular mortality associated with an interquartile range increase in PM2.5 mass and selected PM2.5 components for lag days 0 and 3 , stratified by education. $\mathrm{Cu}$, copper; EC, elemental carbon; Fe, iron; $\mathrm{HS}$, high school; IQR, interquartile range; $\mathrm{K}$, potassium; $\mathrm{NO}_{3}$, nitrates; $\mathrm{OC}$, organic carbon; $\mathrm{PM}$, particulate matter; $\mathrm{SO}_{4}$ sulphates; $\mathrm{Zn}$, zinc. ${ }^{*} \mathrm{p}<0.10$ and ${ }^{* *} p<0.05$ for difference from null effect.

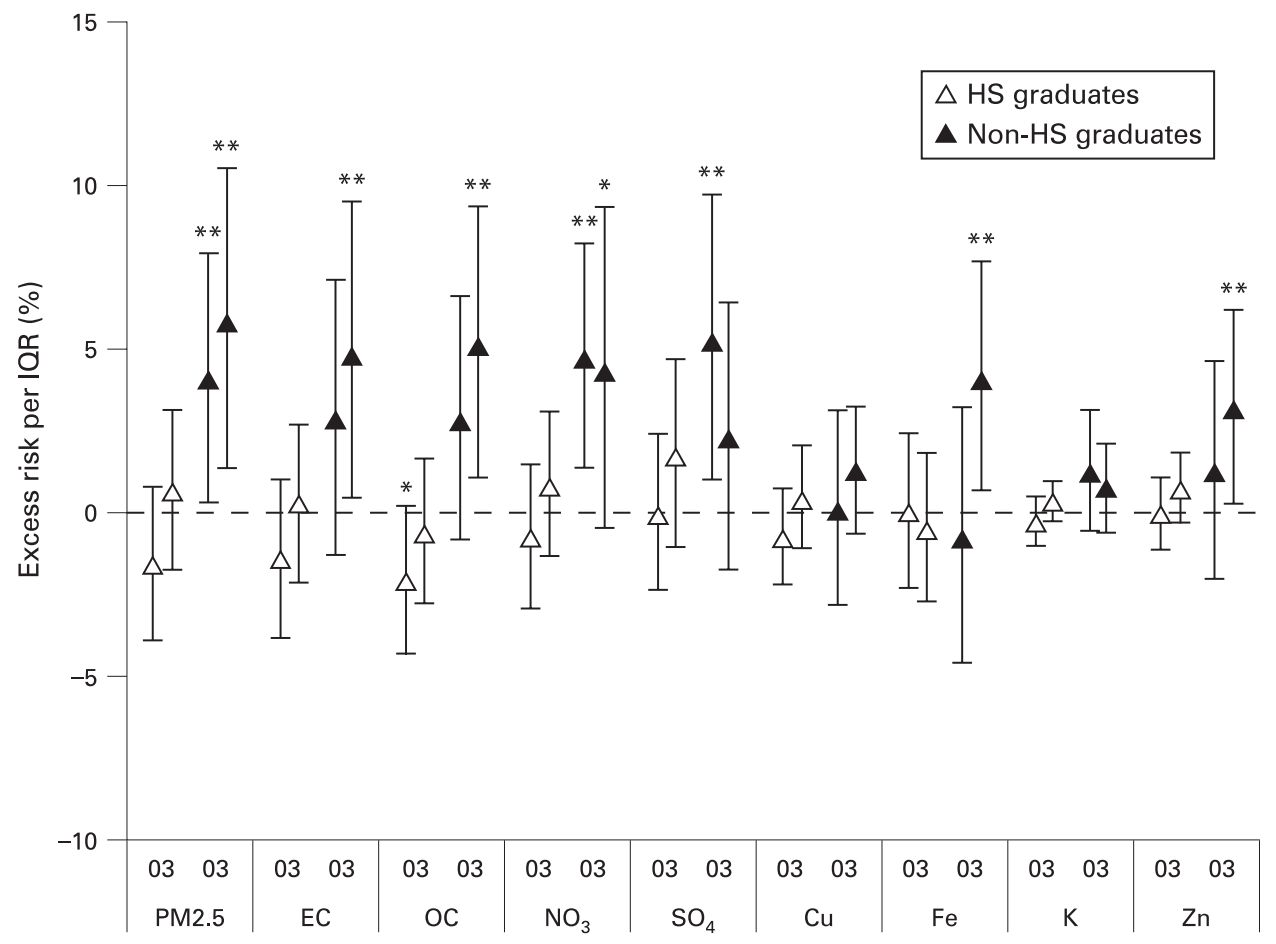

Species (single day lags 0 and 3 ) 
Table 3 Summary of statistically significant positive associations between cardiovascular mortality, by effect modifier and single-lag days for pollutants:

\begin{tabular}{|c|c|c|c|c|c|c|c|}
\hline \multirow[b]{2}{*}{ Pollutant } & \multirow[b]{2}{*}{ All } & \multicolumn{2}{|l|}{ Gender } & \multicolumn{2}{|l|}{ Race } & \multicolumn{2}{|l|}{ Education } \\
\hline & & Male & Female & White & Hispanic & $\begin{array}{l}\text { High school } \\
\text { graduate }\end{array}$ & $\begin{array}{l}\text { Non-high school } \\
\text { graduate }\end{array}$ \\
\hline PM2.5 & $3 \dagger$ & - & $2 \uparrow, 3 \dagger$ & $3^{*}$ & $1 \uparrow, 3 \dagger$ & - & $0 \dagger, 3 \dagger$ \\
\hline $\begin{array}{l}\text { Elemental } \\
\text { carbon }\end{array}$ & $2 \dagger$ & $2^{*}$ & $3^{*}$ & $2 \dagger$ & - & $2^{*}$ & $3 \dagger$ \\
\hline $\begin{array}{l}\text { Organic } \\
\text { carbon }\end{array}$ & - & - & $3 \dagger$ & $2 \dagger$ & - & - & $3 \dagger$ \\
\hline Nitrates & $3^{*}$ & - & $3^{*}$ & - & $1 \dagger, 3 \dagger$ & - & $0 \dagger, 3^{*}$ \\
\hline Sulphates & $3 \uparrow$ & $0^{*}$ & - & $3^{*}$ & $1 \dagger$ & - & $0 \dagger, 2 \dagger$ \\
\hline Calcium & - & - & $2^{*}$ & - & - & - & - \\
\hline Chlorine & - & - & - & - & $2 \dagger$ & - & - \\
\hline Copper & - & - & - & - & $1 \uparrow, 3^{*}$ & - & $1 \dagger$ \\
\hline Iron & $2 \dagger$ & - & $2 \uparrow, 3^{*}$ & $2 \dagger$ & - & $2^{*}$ & $3 \dagger$ \\
\hline Potassium & $2^{*}$ & - & $2 \uparrow$ & $2 \dagger$ & $1 \dagger$ & - & $1 \dagger, 2^{*}$ \\
\hline Sulphur & $3^{*}$ & $0 \dagger$ & $2 \dagger$ & $0^{*}$ & $3^{*}$ & - & $0 \dagger, 2 \dagger$ \\
\hline Silicon & - & - & - & - & - & - & $3 \dagger$ \\
\hline Titanium & $2^{*}$ & - & $2^{*}$ & $2 \dagger$ & $1 \dagger$ & - & $1 \dagger$ \\
\hline Zinc & $3 \uparrow$ & $0 \dagger, 2 \dagger$ & $3 \dagger$ & $3 \dagger$ & - & - & $3 \dagger$ \\
\hline
\end{tabular}

PM, particulate matter.

${ }^{*} p<0.10$ and $\dagger p<0.05$ for difference from null effect.

Numbers in the table indicate which lags (of 0 to 3 days) were statistically significant. Bold indicates that the lag also produced a significantly greater effect estimate $(p<0.10)$ in this group versus the corresponding demographic subgroup.

The regression model includes time (4 df/year), 1-day lags of temperature and humidity, day of week and pollutant.

Particulate metal emissions may be generated from several stages of motor vehicle operations, including fuel combustion, lubrication oil emissions, brake wear and tire dust. ${ }^{20}$ Existing studies provide evidence of adverse effects for several of these metals. For example, transition metals may generate adverse health consequences based on their potential for producing reactive oxygen species and oxidative stress. ${ }^{21}$ Elevated levels of $\mathrm{Cu}, \mathrm{Fe}$ and $\mathrm{Zn}$ generated from a steel mill were among PM constituents associated with mortality and morbidity in Utah Valley. ${ }^{22}$ These elevated levels were associated with in vitro oxidative stress and release of pro-inflammatory mediators by cultured respiratory epithelial cells in aqueous extracts. Huang et $a^{23}$ found that exposure to a factor including $\mathrm{V}, \mathrm{Zn}$ and $\mathrm{Cu}$ from concentrated ambient particles was associated with an increase in blood fibrinogen. Examining relationships between lung function and both ambient PM2.5 and several metals in a panel of individuals with chronic obstructive pulmonary disease, Lagorio et $a^{24}$ reported that daily exposures to $\mathrm{Zn}, \mathrm{Fe}$ and $\mathrm{Ni}$ were associated with decrements in both forced vital capacity and forced expiratory volume in $1 \mathrm{~s}$. Our analysis also indicates associations of potassium with cardiovascular mortality (table 3). Particulate potassium is generally considered as a marker of vegetative burning, including residential wood combustion. ${ }^{25} 26$ In future work, we will use chemical mass balance models to examine associations of particle sources, rather than specific species, with mortality in the six California counties.

We found that for many fine particle species, sociodemographic factors modified the associations of the pollutants with cardiovascular mortality. In particular, we observed greater effect estimates for components of PM2.5 among individuals with lower educational attainment. With some exceptions, similar findings for effect modification by lower educational attainment have been reported in observational mortality studies involving both short- and long-term exposures to particulate matter. For example, in a study of four US cities, ${ }^{27}$ the daily association of PM10 with total mortality was greater for persons with low education. Effect modification of the pollutant-mortality relationship was also examined in an analysis of the 90 largest US cities. ${ }^{5}$ In multivariate models that included city average pollution concentrations of PM10 and nitrogen dioxide, the percentage of the population that had not graduated from high school, was associated with higher cityspecific effect estimates. In a study of 20 cities, most from the eastern United States, Zeka et al28 examined associations between PM10 and daily mortality for various sociodemographic strata, including gender, race and education. For deaths from cardiovascular disease, the PM10 effect estimate was greater for black versus white individuals, and for non-high school graduates. A study in Rome, Italy ${ }^{29}$ demonstrated that the association of PM10 with mortality was most pronounced among those of lower socioeconomic status (SES).

Support for effect modification by SES is also provided by time-series studies of hospitalisation. For example, associations between air pollution and respiratory admissions in New York City and Los Angeles were stronger among Medicaid and MediCal (California's equivalent of Medicaid) recipients than among privately insured individuals. ${ }^{30} 31$ Lower educational attainment also appears to be an important effect modifier in several cohort studies that have examined associations of longer-term exposure to particulate matter with mortality. ${ }^{32}$ Thus, the evidence to date from studies of both short- and longterm exposure suggests that there may be a greater effect of PM among individuals from lower SES groups.

Although the specific risk factors are unknown, plausible candidates include poor nutrition, differential exposure patterns, ${ }^{8}{ }^{33} 34$ greater prevalence of co-morbidities and/or various factors related to poverty, including lower access to and use of healthcare. ${ }^{35-37}$ In the USA, lower income and educational attainment are associated with both more cardiovascular events (eg, nonfatal myocardial infarction, nonfatal ischaemic stroke, cardiovascular death and coronary revascularisation) and higher levels of cardiovascular risk factors (eg, body mass index, hypertension, diabetes and blood lipid levels). ${ }^{38}$ In the six California counties studied, almost $50 \%$ of Hispanic individuals aged $\geqslant 25$ did not graduate from high school, versus $25 \%$ for the 
black population and $12 \%$ for the white population. ${ }^{39}$ Data from the nationwide Behavioral Risk Factor Surveillance System (BRFSS), an ongoing random-digit dialling telephone survey conducted monthly within each state and compiled by the US Centers for Disease Control and Prevention (CDC), show disparities in health behaviours by ethnicity and education. ${ }^{40}{ }^{41}$ In 2004, respondents with less than a high school education from all states combined, were more likely than those with at least a high school education to report current smoking, physical inactivity and obesity. Results of the 2001 BRFSS for California showed that non-Hispanic black and Hispanic participants had higher rates of obesity $(33.9 \%$ and $29.0 \%$, respectively) than non-Hispanic white participants $(20.2 \%)$. Hispanic participants had the highest prevalence of no leisuretime activity and binge drinking, while non-Hispanic black participants had the highest prevalence of current smoking (23.2\%), followed by $17.4 \%$ for white participants and $16.0 \%$ for Hispanic participants.

As has been the case in other studies, we failed to find consistent evidence for pollutant effect modification by gender. For example, in a study of emergency visits for myocardial infarction in 21 US cities, Zanobetti and Schwartz found that effect size for PM10 for males was almost double that of females. ${ }^{42}$ However, in a study of PM10 and mortality in four large US cities, Zanobetti and Schwartz found that the effect estimate linking PM10 with female deaths was greater than that for males. ${ }^{27}$

Our analysis is subject to several limitations. First, the dataset is relatively small, with only about 350 observations per county over a 4-year period. This increases the likelihood of both Type II errors due to low statistical power and Type I errors from stochastic variability with small numbers. These possibilities are somewhat reduced by the use of six counties in the metaanalysis, but the results may still be sensitive to the sampling period; different findings might result from the analysis of larger datasets. For example, in a previous analysis of PM2.5 and mortality, ${ }^{1}$ we found generally similar effect estimates for Hispanic individuals versus white individuals. Consistent with our current findings on PM2.5 constituents, however, our previous study found that for all-cause mortality, the effect estimates for non-high school graduates were more than twice those of high school graduates. A second limitation involves the issue of causality. While some PM2.5 constituents are clearly toxic in a variety of studies (eg, EC), others have less intrinsic toxicity at low levels of exposure (eg, K). Therefore, to the extent that the associations we observed represent causal relationships, the effect of any single PM2.5 component may be due to that component's intrinsic toxicity or from its covariation with other, more toxic substances. Third, the components have differential measurement error owing to differences in the instrumental accuracy and in spatial variability, both of which could bias the resulting effect estimates and standard errors. We also examined the possibility that the apparent effect modification could be due to differences in exposure misclassification. Specifically, if pollution monitors were consistently located in neighbourhoods with high percentages of Hispanic people and individuals who had not graduated from high school, it is possible that these groups would have lower exposure misclassification and greater pollutant-associated effect estimates (assuming the existence of a causal relationship). We first examined the proportion of these subgroups living within $5 \mathrm{~km}$ of the monitors in each county, and compared that to the proportion of the subgroup in the county as a whole. We then limited our meta-analyses to counties where Hispanic people and less-educated populations were not overrepresented near the monitors, and still found greater effect estimates in those subgroups. It is therefore reasonable to conclude that potential differential exposure misclassification had little impact on the observed results.

Our findings provide additional evidence linking daily mortality with combustion-associated particulate matter, as indicated by increased effect estimates for PM2.5 species such as $\mathrm{EC}, \mathrm{OC}, \mathrm{NO}_{3}, \mathrm{~K}$ and several metals, including $\mathrm{Cu}, \mathrm{Fe}$ and $\mathrm{Zn}$. The results also suggest the possibility of increased susceptibility to PM2.5 among specific demographic subpopulations, as signalled by elevated effect estimates for those with less than a high school education and for Hispanic people.

Acknowledgements: The opinions expressed in this paper are solely those of the authors and do not represent the policy or position of the State of California or the California Environmental Protection Agency.

Competing interests: None.

\section{REFERENCES}

1. Ostro B, Broadwin R, Green $S$, et al. Fine particulate air pollution and mortality in nine California counties: results from CALFINE. Environ Health Perspect 2006:114(1):29-33.

2. Schwartz J, Dockery DW, Neas LM. Is daily mortality associated specifically with fine particles? J Air Waste Manag Assoc 1996;46(10):927-39.

3. Ostro B, Feng WY, Broadwin R, et al. The effects of components of fine particulate air pollution on mortality in California: results from CALFINE. Environ Health Perspect 2007:115(1):13-19.

4. Thurston GD, Ito K, Mar T, et al. Workgroup report: workshop on source apportionment of particulate matter health effects--intercomparison of results and implications. Environ Health Perspect 2005:113(12):1768-74.

5. Samet JM, Zeger SL, Dominici F, et al. The National Morbidity, Mortality, and Air Pollution Study. Part II: Morbidity and mortality from air pollution in the United States. Res Rep Health Eff Inst 2000;94(Pt 2):5-70; discussion 71-9.

6. Ecob R, Smith GD. Income and health: what is the nature of the relationship? Soc Sci Med 1999:48(5):693-705.

7. Haan M, Kaplan GA, Camacho T. Poverty and health. Prospective evidence from the Alameda County Study. Am J Epidemiol 1987;125(6):989-98.

8. Morello-Frosch R, Jesdale BM. Separate and unequal: residential segregation and estimated cancer risks associated with ambient air toxics in U.S. metropolitan areas. Environ Health Perspect 2006;114(3):386-93.

9. Ponce NA, Hoggatt KJ, Wilhelm M, et al. Preterm birth: the interaction of trafficrelated air pollution with economic hardship in Los Angeles neighborhoods. Am J Epidemiol 2005;162(2):140-8.

10. National Oceanic and Atmospheric Administration (NOAA). National Climatic Data Center. Climate Resources. http://www.ncdc.noaa.gov/oa/climate/ climateresources.html, 4 April 2005.

11. Health Effects Institute. Revised Analysis of the National Morbidity, Mortality, and Air Pollution Study (NMMAPS), Part II. Revised analysis of time-series studies of air pollution and health. Special report. Boston: Health Effects Institute, 2003:9-72.

12. DerSimonian R, Laird N. Meta-analysis in clinical trials. Control Clin Trials 1986; 7(3):177-88.

13. Schenker $\mathbf{N}$, Gentleman JF. On judging the significance of differences by examining the overlap between confidence intervals. The American Statistician 2001;55(3):182-6.

14. Laden F, Neas LM, Dockery DW, et al. Association of fine particulate matter from different sources with daily mortality in six U.S. cities. Environ Health Perspect 2000; 108(10):941-7.

15. Gold DR, Litonjua AA, Zanobetti A, et al. Air pollution and ST-segment depression in elderly subjects. Environ Health Perspect 2005;113(7):883-7.

16. Lanki T, de Hartog JJ, Heinrich J, et al. Can we identify sources of fine particles responsible for exercise-induced ischemia on days with elevated air pollution? The ULTRA study. Environ Health Perspect 2006;114(5):655-60.

17. Henneberger A, Zareba W, Ibald-Mulli A, et al. Repolarization changes induced by air pollution in ischemic heart disease patients. Environ Health Perspect 2005;113(4):440-6

18. Fairley D. Daily mortality and air pollution in Santa Clara County, California: 19891996. Environ Health Perspect 1999;107(8):637-41.

19. Burnett RT, Brook J, Dann T, et al. Association between particulate- and gas-phase components of urban air pollution and daily mortality in eight Canadian cities. Inhal Toxicol 2000;12(Suppl 4):15-39.

20. Schauer JJ, Lough GC, Shafer MM, et al. Characterization of metals emitted from motor vehicles. Res Rep Health Eff Inst 2006(133):1-76; discussion 77-88.

21. Schlesinger RB, Kunzli N, Hidy GM, et al. The health relevance of ambient particulate matter characteristics: coherence of toxicological and epidemiological inferences. Inhal Toxicol 2006;18(2):95-125.

22. Ghio AJ. Biological effects of Utah Valley ambient air particles in humans: a review. J Aerosol Med 2004;17(2):157-64. 
23. Huang YC, Ghio AJ, Stonehuerner J, et al. The role of soluble components in ambient fine particles-induced changes in human lungs and blood. Inhal Toxicol 2003;15(4):327-42

24. Lagorio S, Forastiere F, Pistelli $\mathrm{R}$, et al. Air pollution and lung function among susceptible adult subjects: a panel study. Environ Health 2006;5:11.

25. Maykut NN, Lewtas J, Kim E, et al. Source apportionment of PM2.5 at an urban IMPROVE site in Seattle, Washington. Environ Sci Technol 2003;37(22):5135-42.

26. Watson JG, Chow JC, Houck JE. PM2.5 chemical source profiles for vehicle exhaust, vegetative burning, geological material, and coal burning in Northwestern Colorado during 1995. Chemosphere 2001:43(8):1141-51.

27. Zanobetti A, Schwartz J. Race, gender, and social status as modifiers of the effects of PM10 on mortality. J Occup Environ Med 2000;42(5):469-74.

28. Zeka A, Zanobetti A, Schwartz J. Individual-level modifiers of the effects of particulate matter on daily mortality. Am J Epidemiol 2006;163(9):849-59.

29. Forastiere F, Stafoggia M, Tasco C, et al. Socioeconomic status, particulate air pollution, and daily mortality: Differential exposure or differential susceptibility. Am J Ind Med 2007;50(3):208-16.

30. Gwynn RC, Thurston GD. The burden of air pollution: impacts among racial minorities. Environ Health Perspect 2001;109(Suppl 4):501-6.

31. Nauenberg E, Basu K. Effect of insurance coverage on the relationship between asthma hospitalizations and exposure to air pollution. Public Health Rep 1999:114(2):135-48.

32. Krewski D, Burnett RT, Goldberg M, et al. Reanalysis of the Harvard Six Cities Study and the American Cancer Society Study of Particulate Air Pollution and

Mortality: A Special Report of the Institute's Particle Epidemiology Reanalysis Project. Cambridge, MA: Health Effects Institute, 2000
33. Green RS, Smorodinsky S, Kim JJ, et al. Proximity of California public schools to busy roads. Environ Health Perspect 2004;112(1):61-6.

34. Morello-Frosch R, Pastor M Jr, Porras C, et al. Environmental justice and regional inequality in southern California: implications for future research. Environ Health Perspect 2002;110(Suppl 2):149-54.

35. Bertoni AG, Goonan KL, Bonds DE, et al. Racial and ethnic disparities in cardiac catheterization for acute myocardial infarction in the United States, 1995-2001. J Natl Med Assoc 2005;97(3):317-23.

36. Callahan ST, Hickson GB, Cooper WO. Health care access of Hispanic young adults in the United States. J Adolesc Health 2006;39(5):627-33.

37. Trivedi AN, Zaslavsky AM, Schneider EC, et al. Trends in the quality of care and racial disparities in Medicare managed care. N Engl J Med 2005;353(7):692-700.

38. Albert MA, Glynn RJ, Buring J, et al. Impact of traditional and novel risk factors on the relationship between socioeconomic status and incident cardiovascular events. Circulation 2006:114(24):2619-26.

39. U.S. Census Bureau. American FactFinder. http://factfinder.census.gov/servlet/ BasicFactsServlet, 2 October 2002.

40. Ahluwalia IB, Mack KA, Murphy W, et al. State-specific prevalence of selected chronic disease-related characteristics--Behavioral Risk Factor Surveillance System, 2001. MMWR Surveill Summ 2003:52(8):1-80.

41. Harper S, Lynch J. Trends in socioeconomic inequalities in adult health behaviors among U.S. states, 1990-2004. Public Health Rep 2007;122(2):177-89.

42. Zanobetti A, Schwartz J. The effect of particulate air pollution on emergency admissions for myocardial infarction: a multicity case-crossover analysis. Environ Health Perspect 2005;113(8):978-82.

\section{Drug and Therapeutics Bulletin (DTB)}

\section{Your key source of unbiased, independent advice}

For over 45 years DTB has been an independent, indispensable part of evidence-based clinical practice. DTB offers healthcare professionals detailed assessment of, and practical advice on, individual medicines and other treatments, groups of treatment and the overall management of disease.

DTB is now also available online at http://dtb.bmj.com:

- browse or search all DTB content from the latest issue back to 1994

- email alerting, sophisticated searching, RSS feeds and full text links from cited references

- interactive services such as My Folders for quick access to articles that you have viewed previously and My Searches to save and re-use useful searches

- comment online on any DTB article

To subscribe, or for further information, please visit http://dtb.bmj.com 